\title{
Gestão da sustentabilidade em Meia Praia - Itapema (SC) sob a percepção dos visitantes e agentes locais
}

\author{
Sustainability management in Meia Praia - Itapema (SC, Brazil) on the \\ perception of visitors and local staff
}

\section{Maria Emília Martins da Silva, Francisco Antônio dos Anjos}

\begin{abstract}
RESUMO
O presente artigo traduz os resultados de uma pesquisa realizada no espaço turístico Meia Praia, bairro do município de Itapema, litoral centro norte do Estado de Santa Catarina sobre as implicações ambientais advindas da evolução urbana. A investigação buscou conhecer o processo de desenvolvimento da atividade turística e suas implicações ambientais no destino, por meio da percepção dos agentes envolvidos com a atividade turística na localidade. $O$ trabalho foi desenvolvido no período compreendido entre março e junho do ano de 2007 . Os métodos de pesquisa utilizados foram pesquisa bibliográfica e documental, pesquisa qualitativa e observação direta do espaço delimitado no estudo. A discussão teórica do estudo se baseou nos campos do conhecimento de gestão da sustentabilidade e planejamento turístico participativo. Utilizou-se para a análise dos dados a metodologia do "Discurso do Sujeito Coletivo", que proporcionou a caracterização da coletividade por meio do individual. Os objetivos da pesquisa foram alcançados na análise final, compreendendo a percepção dos agentes, os quais enfatizaram a preocupação com os impactos ambientais sobre a praia, sendo considerada o principal atrativo do município e do Bairro Meia Praia pelos visitantes. Foi possível conhecer também algumas das ações planejadas pelo poder público municipal para a melhoria dos serviços de infraestrutura para o destino.
\end{abstract}

PALAVRAS-CHAVE: Gestão da Sustentabilidade; Discurso do Sujeito Coletivo; Destino Turístico.

\begin{abstract}
This paper reflects the results of a survey conducted in tourism area of Meia Praia, a district of Itapema city, north central coast of Santa Catarina on the environmental implications arising from urban development. The research sought to understand the touristic development process and its environmental impact on the target, through the perception of those involved with tourism in the locality. The work was carried out between March and June of 2007 . The research methods used were literature and documental review, qualitative research and direct observation of the limited space in the study. The theoretical discussion of the study was based on knowledge about sustainability management and participative tourism planning. To the data analysis was used the methodology of the Speech of Collective Subject, which provided the characterization of the community through the individual. The aims were achieved in the final analysis, understanding the perception of agents, which emphasized the concern about the environmental impacts on the beach, and that is considered the main attraction of the municipality and the district Meia Praia by visitors. It was also possible to know some planned actions by the municipal government for the improvement of infrastructure services destination.
\end{abstract}

KEYWORDS: Sustainability Management; Speech of Collective Subject; Tourist Destination. 


\section{Contextualização}

O turismo sustentável está sendo consolidado a nível internacional com uma abordagem que deve ser consolidada para que todos os tipos de turismo sejam beneficiados ambientalmente, socialmente e economicamente, de modo a maximizar o "desenvolvimento sustentável". Oyola et al. (2012), explicam que uma prática comum para propiciar a gestão da sustentabilidade em destinações é usar um sistema de indicadores para a concepção e implementação de modelos de turismo, considerados instrumentos úteis para diagnosticar a situação do destino, e avaliar as questões que necessitam melhorar o nível de sustentabilidade.

A atividade turística vem ocupando excelente posição na conjuntura econômica mundial, a $52^{\underline{a}}$ posição entre os 139 países avaliados em 2011, e a $10^{\underline{a}}$ posição no PIB mundial, segundo o último relatório elaborado pelo Fórum Econômico Mundial (BRASIL,2012). Nesta perspectiva, entende-se turismo uma atividade econômica em pleno desenvolvimento que depende dos recursos naturais, especialmente quando ele se desenvolve em regiões costeiras, pois estes recursos passam a ser os atrativos almejados pelo público consumidor bem como pelos investidores, quando os espaços naturais se encontram exuberantes e minimamente inalterados.

Embora o crescimento do turismo seja gradual e importante para a economia de uma localidade, é preciso reconhecer suas transformações espaciais. Oliveira (2002, p. 12), a partir deste princípio esclarece que:

O setor turístico apresentou um crescimento acelerado nas últimas décadas e a produção a ele associada coloca-o entre os principais responsáveis pelas muitas transformações ocorridas no espaço, tais como o desordenamento urbano, as agressões ao meio ambiente e até mesmo as alterações do modo de vida de algumas comunidades.

O comentário do autor corrobora o princípio de que este crescimento desordenado é capaz de comprometer a qualidade do turismo em ambientes anteriormente preservados. Este comprometimento está relacionado com o planejamento deficitário do espaço urbano e especialmente da orla marítima, espaço esse de maior profusão de pessoas nos meses de veraneio, além da inexistência de capacidade de carga instalada na maioria dos destinos turísticos.

Ao abordar a gestão da sustentabilidade, a preservação do meio ambiente deve ser pensada não apenas como uma garantia formal, mas vislumbrando uma qualidade de um amplo potencial de recursos, utilizando-se de critérios de prudência ecológica e humana, tal como enfoca o desenvolvimento sustentável proposto por Sachs (1997). De forma geral, o desenvolvimento sustentável visa adequar termos de estratégias ao desenvolvimento socialmente mais justo, ecologicamente prudente e economicamente eficaz (SANTOS; CAMPOS, 2003). 
O termo, desenvolvimento sustentável, quando relacionado ao turismo, deve estar condizente ao planejamento de todos os fatores operantes ao empreendimento turístico, seja público ou privado, de forma que os atores possam atuar de forma responsável e visando uma qualidade permanente do espaço natural. Ruschmann (2001, p. 27) afirma que "[...] é preciso que o turismo e o ambiente natural encontrem um ponto de equilíbrio, a fim de que a atratividade dos recursos naturais não seja a causa de sua degradação". Corroborando a autora, é necessário ainda atuar na linha de frente com projetos que visem organizar o espaço turístico com finalidades de lazer, recreação e preservação dos ambientes naturais apoiando-se aos recursos naturais, atraindo os visitantes e ao mesmo tempo conscientizando-os a se tornarem agentes responsáveis pela maximização da qualidade ambiental requerida.

A atividade turística propicia o desenvolvimento econômico de municípios com potencial turístico, que vislumbraram na sua capacidade de acolhimento, apelo cultural e belezas naturais uma fonte de renda e geração de novos empregos à população autóctone. Entretanto, é necessário pensar na forma de conduzir este turismo, pois como uma organização produtiva, a atividade turística precisa gerenciar ambientalmente seus recursos, para que possa proporcionar os mesmos benefícios para as próximas gerações, e fazer do turismo uma atividade ao mesmo tempo lucrativa e ambientalmente preservada.

A Organização das Nações Unidas (ONU) (2012) entende que um dos problemas ambientais mais visíveis nos tempos atuais talvez seja a poluição, que segundo Lerípio (2004, p. 08), está atrelada "[...] à existência de padrões de produção e consumo não sustentáveis, aumentando a quantidade e variedade dos resíduos persistentes no ambiente em um ritmo sem precedentes". O autor reafirma ainda que:

Somos a sociedade do lixo, cercados totalmente por ele, mas só recentemente acordamos para este triste aspecto de nossa realidade. [...] nos últimos 20 anos, a população mundial cresceu menos que o volume de lixo por ela produzido. Enquanto de 1970 a 1990 a população do planeta aumentou em 18\%, a quantidade de lixo sobre a Terra passou a ser $25 \%$ maior (LERÍPIO, 2004, p.19).

Tendo como referência alguns dos aspectos discutidos acima, o município de Itapema (SC) foi escolhido como um local de estudo relevante para a análise do sistema turístico e sua gestão sustentável em relação às implicações decorrentes do turismo e do crescimento urbano. Este estudo é importante para verificar a evolução do planejamento urbano, no que diz respeito ao impacto das seguintes ações: implementação do Projeto de Gestão Integrada da Orla Marítima (ORLA), alterações no sistema viário, melhorias no sistema de saneamento básico e fornecimento de água, bem como a imagem projetada do destino no cenário turístico estadual e nacional, destacando Itapema como o $5^{\circ}$ destino mais visitado nos últimos anos no Estado de Santa Catarina (SANTA CATARINA TURISMO S/A, 2009). Nesta posição, no ano de 2007, Ita- 
pema estava em desvalorização no que concerne à gestão sustentável, pois não tinha efetivamente o tratamento de esgotamento sanitário e nem ações de planejamento turístico-ambiental.

A pesquisa enfatizou a questão ambiental, especialmente a poluição da praia, recurso natural de maior relevância no destino. Esta degradação ambiental está relacionada às atividades do turismo no local, dentre outras ineficiências de planejamento governamental. $\mathrm{Na}$ análise deste estudo, percebeu-se a importância que o espaço natural exerce sobre o crescimento e desenvolvimento das localidades turísticas, pois ele é o elemento essencial para a própria instalação dos grupos humanos e para o seu progresso material (OLIVEIRA, 2002).

Após uma percepção prévia e generalizada do município de Itapema em relação à sua atividade turística e a gestão sustentável de seus recursos, a problemática da pesquisa fora identificar a percepção dos moradores locais, proprietários de empreendimentos pertencentes ao trade turístico local e turistas sobre o crescimento acelerado do município e, aos seus impactos negativos no ambiente do bairro de Meia Praia, pertencente a Itapema.

Além dos grupos já mencionados, buscou-se conhecer também a opinião da Secretaria de Turismo e Desenvolvimento Econômico Municipal, da Concessionária de Abastecimento Municipal de Água - Companhia Águas de Itapema e da Fundação Ambiental Costeira de Itapema, sobre a alta demanda de visitantes no destino, que vem a ocasionar danos ao ambiente natural quando não há ações de mitigação oriundas do planejamento urbano, social e turístico.

\section{O destino turístico de Meia Praia - Itapema (SC)}

Itapema está localizada no litoral centro norte do Estado de Santa Catarina, a $60 \mathrm{~km}$ da capital Florianópolis. Possui uma área de $58,6 \mathrm{~km}^{2}$, apresentando como limites ao norte o município de Balneário Camboriú, ao sul o município de Porto Belo, a leste o Oceano Atlântico e a oeste o município de Camboriú.

O Programa de Regionalização do Turismo, proposto pelo Ministério do Turismo na Gestão 2003 - 2007 e ainda em atividade visa segmentar os produtos turísticos do país de acordo com suas especificidades, e neste modelo Itapema está incluída no roteiro denominado "Costa Verde e Mar", composto pelos municípios catarinenses: Balneário Camboriú, Itapema, Bombinhas, Porto Belo, Itajaí, Penha e Balneário Piçarras, com uma grande visibilidade turística nacional e internacional, com turistas provenientes, sobretudo do MERCOSUL. O município possui população fixa de 45.797 habitantes segundo o Instituto Brasileiro de Geografia e Estatística (IBGE) (2010) (Tabela 1). Verifica-se que a população praticamente duplica seu número a cada 10 anos, o que pode estar relacionado ao interesse das pessoas em constituir residência fixa neste destino a partir da visitação turística. A população flutuante durante a temporada de verão (período compreendido entre novembro a fevereiro), de acordo 
com informações da Prefeitura Municipal de Itapema (2012), passou de 132.390 na temporada de 2006/2007 para 650.000 em 2010/2011.

Tabela 1- Resumo de população censitária.

Table 1 - Summary of population census.

\begin{tabular}{ccccc}
\hline \multicolumn{5}{c}{ População Censitária } \\
\hline 1970 & 1980 & 1991 & 2000 & 2010 \\
\hline 3.492 & 6.585 & 12.176 & 25.869 & 45.797 \\
\hline
\end{tabular}

Fonte: Instituto Brasileiro de Geografia e Estatística (IBGE) (2010).

Source: Instituto Brasileiro de Geografia e Estatística (IBGE) (2010).

Itapema se desenvolveu economicamente com a inserção da atividade turística, contribuindo com a sua economia atual (pesca), fato que transformou a cidade em destaque no cenário turístico catarinense. Em decorrência disso, ocorreu aceleração do fluxo populacional, que culminou com a especulação imobiliária e o ápice da construção civil. Estes dados alavancaram ações públicas em prol da urbanização do espaço urbano do centro de Meia Praia, mas especialmente da orla marítima, pois se identificou, por meio de observação direta da localidade e pesquisas informais, que Itapema estava entrando em fase de declínio em função da poluição das águas marítimas e fluviais, interferindo negativamente na atividade turística (SILVA, 2007).

O bairro deste município que obteve um crescimento relevante, exclusivo pela atividade turística é denominado Meia Praia, com uma extensão de quase 05 quilômetros de orla marítima, considerado um produto turístico forte para a economia do destino. A Meia Praia se tornou o ponto de maior interesse dos veranistas, motivados pela balneabilidade do mar e das águas calmas, quentes e pouco profundas, pois as demais praias existentes no município apresentam dificuldades de balneabilidade. São elas: Praia do Mar Grosso, da Ihota e da Mata de Camboriú (FARIAS, 1999).

Atualmente, o bairro de Meia Praia apresenta-se com infraestrutura mais diversificada que o núcleo central de Itapema, com destaque maior para a oferta turística do município. Em 2012, o Diário Catarinense - periódico do Estado de Santa Catarina, relatou que a praia de "Itapema fica atrás apenas de Jurerê Internacional, de Florianópolis, como a segunda melhor infraestrutura de praia do Estado" (PREFEITURA MUNICIPAL DE ITAPEMA, 2012).

Ruschmann (2001) enfatiza a importância da atividade turística para a economia de um município, abordando a questão do planejamento do espaço, a gestão dos atrativos e a melhor forma de conduzir esta atividade. Meia Praia, em Itapema, está em uma fase que merece considerável atenção por parte do poder público e iniciativa privada, pois seu crescimento movimentou a economia local por meio do incremento do comércio desde 1995 aproximadamente, e de maneira especial a construção civil 
com seu efeito multiplicador (SECRETARIA DE ESTADO DO PLANEJAMENTO DE SANTA CATARINA, 2007). O desenvolvimento inevitavelmente traz consigo as transformações da paisagem e a sobrecarga de pessoas num ambiente com limites de suporte, que podem comprometer os índices de desenvolvimento costeiro (declínio e rejuvenescimento), segundo o ciclo de vida de uma destinação turística proposto por Butler (1980), além de outras intervenções negativas para o destino.

Por meio da realização desta pesquisa, constatou-se que o principal atrativo ou motivo de visitação de pessoas para o destino é a praia. Em contrapartida, esta é também o principal problema ambiental, tendo em vista a poluição de águas fluviais e àquela proveniente de efluentes domésticos que são lançados ao mar, além da inexistência do planejamento urbano da orla marítima, com construções irregulares à beira mar. Foram observados pontos significativos de poluição visual no bairro, além de outros fatores limitantes para a qualidade de vida da população local e flutuante. A poluição ambiental do município restringe-se à ineficiência do saneamento básico e a poluição visual, que está atrelada ao crescimento desordenado e a quantidade de construções verticais no bairro.

\section{A gestão da sustentabilidade em destinos turísticos}

A gestão do conhecimento da sustentabilidade é uma abordagem que foca as questões fundamentais da adaptação organizacional, da sobrevivência e da competitividade frente às mudanças climáticas inconstantes (COOPER; HALL; TRIGO, 2011). É mensurável sua evolução no campo do conhecimento, quando tem aplicabilidade prática e científica nas esferas públicas e privadas, visando o bem comum de uma sociedade. Desenvolvimento sustentável enfatiza uma abordagem holística, equitativa e clarividente à tomada de decisões em todos os níveis (ORGANIZAÇÃO DAS NAÇÕES UNIDAS, 2012).

O turismo, como atividade econômica do terceiro setor, está envolto com a gestão da sustentabilidade, e sua atuação pode ser justificada como um dos maiores segmentos econômicos do mundo, sendo objeto de atenção em relação à sua potencial contribuição para o desenvolvimento sustentável e ao mesmo tempo quanto aos impactos que pode provocar nos campos ambiental, sociocultural e econômico (ASSOCIAÇÃO BRASILEIRA DE NORMAS TÉCNICAS, 2004, p.4).

De acordo com o Instituto da Hospitalidade (IH) (2004), o turismo tem como matéria-prima de suas atividades primárias os recursos naturais. Porém, por ser um segmento de prestação de serviços, tem seus ativos intangíveis inseparáveis uns dos outros, na busca de um serviço de qualidade para o cliente final. O conhecimento abordado neste enfoque requer informações sobre o destino, os recursos naturais e artificiais existentes, além de sua atratividade no que concerne à sustentabilidade. Tudo isso deve culminar na perspectiva de acolhimento das pessoas, que são o públicoalvo do segmento turístico. 
No espaço turístico, as alterações sociais, culturais e ambientais são também inconstantes, uma vez que há interferências internas e externas muito frequentes, contribuindo para o desenvolvimento do turismo ou o prejudicando.

Numa perspectiva voltada para a gestão da sustentabilidade, é inevitável que se modifiquem as localidades turísticas, principalmente quando se torna necessário a construção e instalação de serviços para atender o turista. Muitas vezes, ocorre o desrespeito com o uso e com a ocupação do solo, devido à improvisação nas instalações e o desrespeito às leis ambientais municipais. A partir da análise de documentos como, por exemplo, o Plano Diretor, é possível usar do conhecimento explícito para a tomada de decisão e assim, minimizar situações limitantes acerca do nãoplanejamento do espaço turístico.

Cooper, Hall e Trigo (2011, p.133) afirmam que

no caso do turismo, as mudanças ambientais tornam-se nítidas, não só por conta da turbulência no ambiente de fornecimento, mas também por conta das oscilações na conduta dos turistas.

O desenvolvimento sustentável, e mesmo outras formas de planejamento, estão apoiados na busca pela qualidade da atividade produtiva, industrial ou turística, que, segundo Callenbach et al.(1993, p.36):

[...] consiste no atendimento de requisitos de natureza física, química, biológica, social, econômica e tecnológica que assegurem a estabilidade das relações ambientais no ecossistema no qual se inserem as atividades da organização.

Porém, Backer (1995, p.14) apresenta uma definição mais abrangente para a gestão da sustentabilidade, a qual implica a "administração do uso dos recursos ambientais, por meio de ações ou medidas econômicas, investimentos e providências institucionais e jurídicas, com a finalidade de manter ou recuperar a qualidade dos recursos e o desenvolvimento social".

No campo da gestão do conhecimento, o exercício da percepção é que dará subsídios para reconhecer o conhecimento explícito, e através dele, obter subsídios para a tomada de decisões gerenciais. Para Lerípio e Campos (2009), a percepção ambiental é uma atividade mental de interação do indivíduo com o ambiente, que ocorre através de mecanismos perceptivos propriamente ditos e, principalmente, cognitivos.

A gestão ambiental constitui atualmente um importante fator de ponderação na alta administração das empresas e na pauta da administração pública, principalmente pela exigência da sociedade contemporânea. No campo do turismo, é preciso ressal- 
tar que todas as intervenções desta atividade num determinado espaço não se traduzem, necessariamente, na agressão ou na degradação do ambiente natural. Qualquer mutação econômica ou social, independentemente de sua origem, pode provocar modificações na relação do homem com seu espaço, seja ele positivo ou limitante (RUSCHMANN, 2001).

O turismo de massa, hoje uma realidade cada vez mais presente nas localidades turísticas se difundiu mundialmente por volta de 1960, quando milhares de pessoas começaram a usufruir seu tempo livre, aliado às melhores condições de renda para as viagens de lazer (ORGANIZAÇÃO MUNDIAL DO TURISMO, 1994). Em vista disso, esta aglomeração de pessoas em determinados locais vem apresentando responsabilidade relevante na degradação dos recursos naturais em destinações turísticas. Nesta perspectiva, Ruschmann (2001, p.110) constata que:

\begin{abstract}
O excesso de turistas conduz ao superdimensionamento dos equipamentos destinados a alojamento, alimentação, transporte e entretenimento, que impreterivelmente ocupam grandes espaços - agredindo paisagens e destruindo ecossistemas. Além disso, a falta de cultura turística dos visitantes faz com que se comportem de forma alienada em relação ao meio que visitam - acreditam que não tem nenhuma responsabilidade na preservação da natureza e na originalidade das destinações. Entendem que seu tempo livre é sagrado, que tem o direito ao uso daquilo pelo qual pagaram e que, além disso, permanecem pouco tempo - tempo insuficiente, no seu entender, para agredir o meio natural.
\end{abstract}

Para Dias (2003), não resta dúvida que a massificação do turismo contribuiu decisivamente para a expansão dos problemas ambientais nos destinos turísticos tradicionais, pois o crescimento do turismo exige a projeção de toda uma infraestrutura e equipamentos, como construção e melhoria da rede viária, aeroportos, rodoviárias, redes de esgoto e de água potável, energia elétrica, hotéis, restaurantes, comércio, entre outros.

Entende-se desta forma, que a atividade turística impacta o ambiente natural quando não planejada, estando associada a fatores como: poluição do ar por meio da emissão de gases e fumaça; poluição da água por resíduos líquidos e sólidos (que saturam a rede de esgoto e contaminam o lençol freático); poluição das águas por derramamento de óleos e outros produtos químicos; poluição sonora e visual, pelo acúmulo de pessoas ao mesmo tempo e no mesmo lugar; alterações na estrutura e composição do solo; erosão física do solo; impactos ecológicos e geológicos associados com o excesso de construções; diminuição da beleza visual; esgotamento de água potável; perturbação da população autóctone, desordenamento urbano; entre outras. 
Embora exista legislação para o controle e fiscalização, cujos objetivos são orientar e fiscalizar o uso e ocupação do solo, bem como administrar os recursos naturais, zoneamento urbano, ocupação do território; ainda se faz necessário levantar a capacidade de carga de algumas destinações e planejar a atividade turística, de modo que ela não venha a prejudicar outros setores da economia, nem tampouco se reverter contra si mesma.

Um exemplo é a Resolução do Conselho Nacional do Meio Ambiente (CONAMA) - $\mathrm{n}^{\circ} 237$, de 19 de dezembro de 1997, que aborda em seus Artigos $2^{\circ} \mathrm{e}$ $3^{\circ}$, estabelecendo a necessidade da licença ambiental para empreendimentos e atividades utilizadoras de recursos ambientais e potencialmente causadores de degradação. Observa-se, neste sentido, que muitos empreendedores procuram por destinos com delicado equilíbrio ambiental para se fixar e acabam se esquecendo de manter uma conduta ambiental responsável para com a sociedade, aproveitando da morosidade burocrática dos setores públicos de controle e fiscalização. Portanto, para desenvolver um modelo sustentável para o turismo, a gestão eficiente é necessária a fim de verificar como os impactos são frequentemente monitorados, permitindo que medidas corretivas e preventivas sejam introduzidas no destino (WTC, 2004).

Neste enfoque, a gestão da sustentabilidade constitui-se em um novo imperativo, o que reforça a oportunidade para mais uma vantagem competitiva, além de uma necessidade iminente (KANNI, 2004). Para as empresas ligadas ao turismo, a gestão deve adotar práticas de mínimo impacto sobre o ambiente natural, monitorando e minimizando efetivamente os conflitos, de forma a contribuir para a manutenção das dinâmicas e processos naturais em seus aspectos paisagísticos, físicos e biológicos, considerando o contexto social e econômico existente (ASSOCIAÇÃO BRASILEIRA DE NORMAS TÉCNICAS, 2004). Considera-se, portanto, que o turismo sustentável não se dá apenas por processos de gestão, mas também pelas condutas de consumo, ética e de hospitalidade de toda a sociedade.

\section{A importância da gestão turística participativa}

O planejamento de um destino turístico requer a participação de todos os atores envolvidos com a atividade turística, de modo que possam se envolver com os planos e metas direcionadas para o objetivo proposto. Este planejamento precisa conceber o turismo como um processo complexo, entendido na sua totalidade a partir de uma visão integradora, multidisciplinar e sistêmica (ANJOS; ANJOS; RADOS, 2010). Oyola et al. (2012) dizem que numa abordagem sistêmica de planejamento, os indicadores de turismo sustentável podem ter usos múltiplos como ferramentas práticas de planejamento, cuja aplicação deve ser decidida pelos gestores locais, enfatizando o estabelecimento de práticas de referência para o destino, como por exemplo o benchmarking.

A implantação do planejamento participativo é difícil, Molina (2001) ensina que particularmente na América Latina esta modalidade de planejamento é uma necessi- 
dade latente, mas na mesma força se apresenta como dificuldade, haja vista o nível de descentralização do poder necessária para esta tomada de decisões, e ainda o receio ou uma possível intimidação da comunidade local deve ser considerada. Em contrapartida, é imprescindível acompanhar a evolução da comunidade e reconhecer sua percepção e anseios acerca do turismo local. Somente assim, este planejamento será eficaz em médio e longo prazo.

Hall (2001), afirma a concepção de que a gestão do desenvolvimento do turismo continua se apresentando como uma ação importante pelos seus efeitos duradouros e marcadamente significativos para os espaços turísticos, trazendo benefícios, principalmente para a comunidade local.

Anjos, Anjos e Rados (2010) enfatizam que a ação do Estado no planejamento do turismo tem grande significado, pois desempenha o papel de coordenador e planejador no desenvolvimento público da atividade turística dentro de diferentes esferas e entre as muitas organizações turísticas governamentais, além do setor privado. Todavia, o governo também pode exercer o papel de empresário no turismo, pois além de fornecer infraestrutura básica, acesso e saneamento, pode ser proprietário e dirigir empreendimentos turísticos.

É relevante destacar que numa sociedade onde se prioriza a gestão da sustentabilidade, conforme relata Santos (2005), o novo papel do Estado está em promover e fiscalizar a sociedade, o qual tem por objetivo [...] apoiar a construção das bases para o desenvolvimento sustentável; promover a melhoria da infraestrutura [...]; entre outras ações. Nesse sentido, tem-se como uma das premissas desta nova sociedade o desenvolvimento sustentável, que envolve as dimensões ambiental, econômica e social, por meio de uma articulação convergente entre as partes.

Portanto, o papel da iniciativa pública é essencial para bem prover um território, buscar o equilíbrio com a sociedade civil e associações de classe, organizações não governamentais, gerindo esforços para suavizar os efeitos negativos decorrentes do desenvolvimento econômico extremista para o bem do ambiente local. Para ações como estas, o planejamento do território e da atividade turística tornam-se fundamentais, fazendo parte da gestão de políticas públicas.

Sachs $(2008$, p.11) enfoca ainda que o Estado tem três funções principais como meio de organizar o território de forma sustentável:

a) a articulação de espaços de desenvolvimento, desde o nível local (que deve ser ampliado e fortalecido) ao transnacional [...];

b) a promoção de parcerias entre todos os atores interessados, em torno de um acordo negociado de desenvolvimento sustentável;

c) a harmonização de metas sociais, ambientais e econômicas, por meio do planejamento estratégico e do gerenciamento cotidiano da economia e da sociedade, buscando um equilíbrio entre diferentes sustenta- 
bilidades (social, cultural, ecológica, ambiental, territorial, econômica e política) e as cinco eficiências (de alocação, de inovação, a keynesiana, a social e a ecoeficiência).

Como é visto, cabe ao estado, além de ações como estas, a diversificação de produtos de qualidade, a formação de recursos humanos e a integração às demais políticas setoriais afins como desenvolvimento econômico e ambiental, as quais estão na pauta da administração pública.

Portanto, deve-se pensar no processo de planejamento e desenvolvimento comprometidos com a preservação ambiental viável economicamente e equitativa do ponto de vista social. A partir da percepção e conhecimento oriundos dos agentes locais é possível construir uma rede de compartilhamento de informações para servir de subsídios para o gerenciamento público e privado. Estas redes fazem a ponte com a gestão do conhecimento, facilitando o fluxo do conhecimento entre sistemas de negócios e de destinos turísticos. Portanto, isso se encaixa perfeitamente para atender as demandas da globalização [...] (COOPER; HALL; TRIGO, 2011).

Todavia, o poder público pode desestimular a iniciativa privada ao criar instrumentos legais sem captar a fundo a essência da atividade turística. Estes instrumentos, face à sua multiplicidade, podem criar dificuldades operacionais para as empresas que atuam no turismo. Sendo um setor novo e dinâmico, o turismo precisa ser constantemente analisado e avaliado para reformulação de suas políticas públicas. Nesta abordagem, encontra-se a necessidade de perceber os anseios da comunidade local (ALEXANDRE, 2003).

A fim de apoiar a gestão pública do turismo em nível municipal, o Plano Diretor proporciona subsídios para o desenvolvimento do turismo, especialmente quanto ao zoneamento urbano, uso racional da água, do solo, etc. Há também a formação do Conselho Municipal de Turismo (COMTUR) que atua como apoio à Secretaria Municipal de Turismo, formado pela sociedade civil, entidades de classe e demais organizações da iniciativa privada, compondo uma gestão participativa, além da composição de Consórcios Municipais que visam um interesse comum.

A participação da população na gestão do desenvolvimento turístico é o ponto de equilíbrio entre a preservação do patrimônio natural e cultural, a viabilidade econômica do turismo e a igualdade social do processo de planejamento participativo (ANJOS, ANJOS e RADOS, 2010). É evidente que o processo de planejamento não pode ficar alheio às aspirações das comunidades ou populações envolvidas, mas deve detectar respostas em seu próprio interior. Por meio do conhecimento de como as pessoas percebem e compreendem os diferentes níveis de espaços urbanos ou rurais são obtidos dados singulares e demonstrativos sobre o modo de desenvolver as atividades e se relacionar com a natureza (LERÍPIO, 2004). Esta estratégia integra a gestão do conhecimento da sustentabilidade. 
Desta forma, é possível neutralizar ou, ao menos minimizar os impactos ambientais em municípios turísticos, contribuindo para o ambiente natural, mas especialmente para a população autóctone, que vive o dia a dia da atividade turística e, certamente depende direta ou indiretamente desta atividade para a sobrevivência.

\section{Materiais e métodos}

O local de estudo possui $05 \mathrm{~km}$ de orla marítima, predominantes em praias arenosas, de águas calmas e pouco profundas, intercaladas por costões rochosos com ocorrência de lajes e recifes rochosos em algumas de suas porções. O espaço analisado foi o bairro de Meia Praia, localizado no município de Itapema, por apresentar características expressivas em relação ao desenvolvimento do turismo e crescimento urbano nas últimas décadas, tornando-se o ponto de maior interesse dos veranistas por suas belezas naturais.

Para alcançar os objetivos da pesquisa, os procedimentos metodológicos utilizados para sua realização estão baseados no estudo de caso, pois, conforme menciona Schramm (1971), a essência de um estudo de caso é tentar esclarecer uma decisão ou um conjunto de decisões: o motivo pelo qual foram tomadas, como foram implementadas e com quais resultados. De acordo com os preceitos de Gonçalves (2004), o método estudo de caso é uma pesquisa exploratória, pois discute a relevância da variável ambiental para o produto turístico.

A pesquisa bibliográfica e documental se fez presente neste estudo, por meio da busca de informações em bibliografias específicas da área do turismo e planejamento turístico. Outras informações pertinentes ao município foram obtidas através de consultas na web, em sites como IBGE, site oficial do município, pesquisa in loco, trabalhos acadêmicos entre outros. Para consubstanciar este método de pesquisa, Minayo $(1999$, p. 53) esclarece que [...] a pesquisa bibliográfica coloca frente a frente os desejos do pesquisador e os autores envolvidos em seu horizonte de interesse.

No estudo de caso, optou-se por aplicar a pesquisa qualitativa, no que tange ao levantamento de dados, pois existe a necessidade de selecionar um determinado grupo de pessoas, a fim de fazer parte da análise pretendida. Neste propósito, foram realizadas entrevistas semi-estruturadas com a comunidade local, proprietários dos empreendimentos turísticos (trade turístico) e turistas (visitantes), com o intuito de identificar suas percepções sobre as transformações do município e suas implicações ambientais.

A pesquisa qualitativa, que delimita parte da coleta de dados, foi aplicada também com os agentes públicos e de apoio à gestão pública - Secretaria de Turismo e Desenvolvimento Econômico Municipal, Concessionária de Abastecimento Municipal de Água - Companhia Águas de Itapema e Fundação Ambiental Costeira de Itapema, considerando todos esses agentes imprescindíveis para a conclusão do estudo.

As metodologias utilizadas para analisar os dados foram baseadas em Léfevre e Léfevre (2003) e Anjos (2004). O roteiro de entrevista foi elaborado segundo a ca- 
racterística dos entrevistados. As questões realizadas durante a pesquisa para os quatro tipos de públicos distintos foram elaboradas a partir das seguintes temáticas:

\section{Turista (Visitante)}

- motivações para a visita ao destino;

- percepção da qualidade dos serviços oferecidos ao visitante;

- percepção da infraestrutura básica (saneamento básico, coleta de lixo, tratamento de esgoto e acessos);

- alterações prejudiciais ao ambiente decorrentes da atividade turística;

- ações para melhoria da infraestrutura e para o desenvolvimento do turismo no destino.

\section{Morador (Autóctone)}

- importância da atividade turística para o município;

- percepção da qualidade dos serviços oferecidos ao visitante;

- aspectos mais relevantes da oferta turística do bairro Meia Praia;

- percepção da infraestrutura básica (saneamento básico, coleta de lixo, tratamento de esgoto e acesso);

- ações para melhoria da infraestrutura e para o desenvolvimento do turismo;

- alterações prejudiciais ao ambiente decorrentes da atividade turística;

- postura ambiental em sua residência.

\section{Agente Privado (Empreendimentos da oferta turística)}

- importância da atividade turística para o município;

- percepção da qualidade dos serviços oferecidos ao visitante;

- aspectos mais relevantes da oferta turística do bairro Meia Praia;

- avaliação da infraestrutura básica (saneamento básico, coleta de lixo, tratamento de esgoto e acesso);

- ações para melhoria da infraestrutura e para o desenvolvimento do turismo;

- alterações prejudiciais ao ambiente decorrentes da atividade turística;

- postura ambiental do empreendimento.

\section{Agente Público e de apoio ao Serviço Público Municipal}

- percepção da qualidade dos serviços oferecidos ao visitante;

- aspectos mais relevantes da oferta turística do bairro Meia Praia como destino turístico;

- avaliação da infraestrutura básica (saneamento básico, coleta de lixo, tratamento de esgoto) para o atendimento ao visitante e aos moradores em períodos de alta concentração de pessoas;

- problemas ambientais prioritários pela gestão pública municipal. 
Para a entrevista foram escolhidos três pontos distintos da orla de Meia Praia. Foram abordados os turistas que estavam aproveitando o espaço natural. Os moradores foram escolhidos aleatoriamente, do centro da Meia Praia e, quanto ao setor privado, foram escolhidos um restaurante, um meio de hospedagem e uma agência de viagens. A entrevista foi realizada com 12 pessoas ao todo, sendo três turistas, três moradores, três representantes do setor privado e três representantes do setor público.

Para a análise das entrevistas realizadas utilizou-se o método do Discurso do Sujeito Coletivo (DSC), o qual é um método de processamento de depoimentos e demais materiais verbais (artigos de jornal, de revista, etc.) que procura constituir e descrever o pensamento de coletividades ou grupos sociais, sob a forma de discursos coletivos que expressam as distintas representações sociais existentes numa dada formação social sobre um dado tema de pesquisa, constituindo a abordagem interpretativa da realidade social (LEFÉVRE; LEFÉVRE, 2003). A metodologia escolhida possibilitou identificar a interpretação dos turistas (frequentadores do produto), da população local e dos agentes públicos e privados investigados no campo delimitado, pois o DSC faz produzir o sujeito social ou coletivo do discurso e o discurso correspondente, fazendo o coletivo falar a partir do individual. Esta metodologia foi empregada na pesquisa, tendo em vista a característica própria e indissociável do pensamento coletivo, sendo este discurso redigido na primeira pessoa do singular e composto por expressões-chaves, que têm a mesma ideia central ou ancoragem (LEFEVRE; LEFÉVRE, 2003). Este método preserva a opinião dos entrevistados em todos os momentos da pesquisa, sendo possível conhecer em profundidade sua percepção acerca do tema pretendido, além de compreender as decisões que estão sendo tomadas em prol do turismo e do ambiente no local.

\section{Resultados e discussão}

Analisar o sistema turístico do bairro de Meia Praia possibilitou entender sua dinâmica como um destino turístico emergente no Estado de Santa Catarina, porém encontrando-se ainda com inúmeras limitações ambientais e problemas de infraestrutura. Anjos (2004), em seu estudo sobre a evolução urbana ambiental de Itapema, diz que o sistema territorial turístico [...] está dividido em subsistemas de modo a organizar o território turístico, e dentre os subsistemas definidos pelo autor, está o subsistema dos fixos naturais, que são aqueles compostos basicamente pelos elementos naturais, mas controlados por dinâmicas não humanas. Segundo o autor, nesse caso, a ação humana pode interferir negativamente ou trabalhar em sua recuperação, como é visto na presente pesquisa. Ele ainda definiu o subsistema dos elementos fixos construídos pelo homem, que são os elementos resultantes das ações humanas sobre os espaços (ANJOS, 2004). Seguindo a linha de pesquisa deste autor, os subsistemas citados estão em evidência no presente estudo, por meio da percepção dos agentes envolvidos diretamente no espaço. As hipóteses de que a praia é o principal motivo 
de visitação, sendo também o principal recurso natural poluído da localidade e o turismo como a base econômica do município foram confirmadas.

Díaz e Rodrígues (2008) afirmam que uma destinação turística constitui uma realidade complexa, que deve ser gerenciada como um sistema integrado, a fim de garantir sua qualidade de visitação para a demanda turística. A busca de avaliações estratégicas frequentes vem propiciar ao destino turístico ser conhecido sob uma perspectiva global. Em vista disso, os autores discutem ainda que é necessário estudar o destino e propor medidas de gestão baseadas na sustentabilidade para que ele possa se tornar competitivo ou ao menos se relançar no contexto organizacional ao qual está inserido, haja vista que a gestão da sustentabilidade é o foco da qualidade dos destinos turísticos na atualidade.

Choi e Sirakaya (2006) corroboram a discussão relatando que os indicadores de avaliação para o desenvolvimento da gestão sustentável de destinos turísticos devem incluir os moradores da localidade, especialistas da indústria local (oferta turística), gestores governamentais e não governamentais, pois as características distintas dos agentes envolvidos no sistema vão indicar o diagnóstico para a tomada de decisão numa gestão participativa.

Este estudo, que teve uma abordagem interpretativa do fenômeno social, onde a essência da interação social está nos significados individuais, foi fundamental para conhecer a realidade social do destino Meia Praia - Itapema a partir da visão dos frequentadores, moradores, gestores e prestadores de serviço do destino. Ainda que os resultados sejam subjetivos, são resultados de estudos científicos, com validade intelectual, base da abordagem interpretativa (HUGHES, 1980). A forma escolhida para a apresentação dos resultados da pesquisa foi delimitar os discursos (DSC) dos entrevistados às questões de maior relevância com o tema central do estudo, confrontando com as demais metodologias também aplicadas, que são apresentadas a seguir:

\section{Percepção coletiva dos turistas (visitantes) - frequentadores do produto Meia Praia}

Primeiramente questionou-se o principal motivo de atração das pessoas ao destino, motivo pelo qual se caracteriza o crescimento acelerado dos visitantes de turismo em períodos de férias ou tempo de lazer. Através das entrevistas e análises do DSC, a praia foi evidenciada como o local de maior atratividade e ponto de encontro de famílias. Aspectos relevantes como a orla, a paisagem, o mar e o ambiente foram mencionados como "agradável" e "motivacional".

Outro questionamento abordou a percepção dos turistas sobre a infraestrutura básica de Meia Praia - direcionada no roteiro de entrevista, como: saneamento básico, acessos, coleta de lixo, etc. Percebeu-se uma contradição nas respostas, ou seja, a percepção de dois dos três entrevistados. O primeiro turista enfatiza a precariedade da infraestrutura, especialmente da estrutura viária (tráfego interno no bairro) e do saneamento básico, fato este que se torna mais perceptível na alta temporada de verão 
pelo grande fluxo de pessoas que visitam a cidade. Os outros dois consideram como "bem estruturado", enfatizando a excelente hospitalidade da comunidade local.

A percepção almejada na terceira questão elencou as alterações mais visíveis e prejudiciais ao ambiente natural da Meia Praia, decorrentes da atividade turística. Os entrevistados relataram sobre o esgoto que é escoado diretamente ao mar, propiciando a poluição da praia (areia e mar). Mais uma vez, o segundo agente demonstra desconhecimento sobre este assunto, pois ele se mantém satisfeito.

Em mais uma questão, buscou-se identificar as ações que poderiam ser tomadas para melhorar os aspectos de infraestrutura e contribuir para o desenvolvimento do turismo no município. Os entrevistados citaram a importância da integração entre o setor público e o privado, especialmente em relação ao controle e fiscalização da construção civil que consiste na edificação sem limites e sem planejamento por parte do setor imobiliário. A limpeza da praia e o escoamento de efluentes domésticos foram citados como ações a serem sanadas por parte da gestão pública municipal.

A percepção dos visitantes e demais entrevistados está atrelada à realidade apresentada no município, enfatizando que esta pesquisa foi realizada no ano de 2007. Aspectos como infraestrutura básica é um ponto eminentemente limitante. A implantação da rede de coleta de esgoto somente foi iniciada no município no ano de 2005 , chegando a $60 \%$ em dezembro de 2007 , haja vista que as tubulações escoam diretamente ao mar. A apresentação da paisagem que integra a orla marítima é precária, sem nenhum planejamento urbano, comprometendo a qualidade visual e a mobilidade das pessoas.

\section{Percepção coletiva dos moradores locais (comunidade autóctone)}

O segundo grupo dos entrevistados foram os moradores de Meia Praia - Itapema, considerados a "comunidade autóctone" ou comunidade local.

O primeiro questionamento aos moradores locais do município foi o mesmo realizado para os turistas, no que consiste a qualidade da infraestrutura urbana. Em relação à estrutura viária do município, fica clara a satisfação dos moradores, quando explicam que a duplicação da BR-101 favoreceu a "visibilidade" e o "acesso" a Meia Praia e a Itapema, entretanto, o saneamento básico e a ineficiência da rede de coleta de esgoto foram relatados como um sério problema no município, principalmente porque a poluição da praia está atrelada a este fator. Relatam ainda que a infraestrutura urbana ainda é ruim, "devendo melhorar o quanto antes", a fim de não prejudicar o principal atrativo da destinação que é a praia.

Outro questionamento foi feito em relação às alterações mais visíveis e prejudiciais ao ambiente de Meia Praia, sob a visão dos moradores do bairro. Verificou-se novamente que a poluição da praia é referenciada como o principal problema e o mais sério, ocasionado pelo escoamento de efluentes domésticos no mar. A orla, por sua vez, também foi citada como um ponto limitante, sem estrutura de lazer para os mora- 
dores e, principalmente para os turistas. Um fator importante citado nas respostas foi a "falta de arborização na praia", que acabaria sendo um diferencial no bairro se a mesma existisse.

Um terceiro discurso descreve a opinião dos entrevistados sobre a qualidade dos serviços de Meia Praia como produto turístico. Percebeu-se que os moradores consideram os serviços "bom", com ressalva para os restaurantes e o comércio. Outro ponto relevante mencionado foi quanto aos hotéis do bairro, que na percepção deles, não se desenvolvem tanto pela quantidade de casas e apartamentos de aluguéis e casas de excursões à disposição dos visitantes, caracterizando a segunda residência.

O discurso apresentado pelos entrevistados não surpreendeu os pesquisadores, pois as respostas obtidas com os moradores do bairro de Meia Praia foram semeIhantes, no que diz respeito a abordagem da praia como aspecto de oferta turística mais relevante e a ineficiência do saneamento básico como fator prejudicial ao ambiente. Também reconhecem ser o turismo o propulsor econômico do município, com seu efeito multiplicador nos setores da construção civil, imobiliário e prestadores de serviços.

\section{Percepção dos proprietários de empreendimentos da oferta turística - prestado- res de serviços}

Pertencentes ao grupo dos empreendimentos privados, foram entrevistados os representantes de um meio de hospedagem, um restaurante e uma agência de viagens, todos localizados no bairro de Meia Praia, os quais tem na atividade turística sua maior demanda de clientes. Esses são parte da oferta turística do município, pertencentes ao sistema turístico local.

A primeira pergunta aos entrevistados do setor privado abordou quais os aspectos da oferta turística são considerados mais relevantes em Meia Praia, tendo como variáveis a praia, a paisagem, a oferta de serviços, a hospedagem e a gastronomia (restaurantes). A praia e a paisagem foram citadas como mais relevantes e, a preocupação em manter este atrativo natural preservado, pois relatam a insatisfação com o saneamento básico do município. Como segunda opção, relataram a oferta de restaurantes, que na percepção deles é satisfatória.

A segunda questão se refere à eficiência da infraestrutura básica de Meia Praia, tendo como variáveis: saneamento básico, coleta de lixo, coleta e tratamento de esgoto e acessos. As respostas foram "regular" e "ruim", com evidência para o saneamento básico. Portanto, na percepção dos empresários, a infraestrutura do bairro é limitante e interfere negativamente na prestação de serviços turísticos.

Estes agentes reconheceram também a importância da atividade turística para o município e consequentemente para suas empresas, alegando o problema da sazonalidade e a preocupação com a poluição da praia, que pode trazer danos mensuráveis ao destino se providências não forem tomadas. 


\section{Percepção dos prestadores municipais de serviços públicos e apoio a gestão pública}

Aos prestadores municipais de serviços públicos e apoio a gestão pública, grupo este formado pela Secretaria Municipal de Turismo, Companhia Águas de Itapema (concessionária municipal de abastecimento de água) e a Fundação Ambiental Área Costeira de Itapema (FAACI), questionou-se se a infraestrutura básica do município é suficiente para atender a demanda de moradores e visitantes em períodos de alta temporada. Em relação ao saneamento básico e abastecimento de água, as respostas foram "agora sim", demonstrando que está melhorando e evoluindo; já o sistema viário da cidade ainda é precário, mas de forma geral, a percepção é de que a cidade está trabaIhando para melhorar a sua estrutura.

O segundo DSC apresenta os principais impactos ambientais considerados prioritários pela gestão pública em Itapema. A poluição da praia (balneabilidade) foi a primeira resposta, estando associada com a falta de esgotamento sanitário; o sistema viário também foi um ponto limitante percebido por todos; o desmatamento de Mata Atlântica (controle dos remanescentes) e o tráfico de animais, segundo a $\mathrm{FAACl}$, é um ato frequente em Itapema e que precisa ser combatido; e as ligações clandestinas de esgoto foram pontos destacados pela companhia de abastecimento de água e esgoto da cidade, demonstrando a ineficiência da fiscalização e, consequentemente, a poluição aos mananciais.

Além dessas, outras considerações relevantes foram levantadas como a priorização do município para a construção civil, e, atrelado a este fator, a inexistência de parques, praças e área verde para a convivência das pessoas. Neste contexto, foi relatado que a atual gestão municipal está realizando estudos para a implantação do Parque Linear integrante do Projeto de Gestão Integrada da Orla Marítima (ORLA), no bairro de Meia Praia. Este projeto é uma iniciativa do Ministério do Meio Ambiente e tem por objetivo a valorização dos espaços da orla costeira, a recuperação da vegetação, construção de espaços públicos de lazer, saneamento ambiental, definição de acessos, entre outros previstos no plano de intervenção.

\section{Considerações finais}

Foi possível verificar a ineficiência da infraestrutura urbana do município, sobretudo pelo crescimento acelerado que ocorreu nas últimas décadas que não acompanhou no mesmo ritmo, em virtude do desenvolvimento turístico no litoral norte do Estado de Santa Catarina. O setor público reconhece que Meia Praia tem um enorme potencial para o turismo e que a deficiência do saneamento básico em especial, tem merecido preocupação quanto à poluição demasiada nas praias, mau cheiro nas ruas, além do tráfego interno limitante. Os responsáveis relataram que ações estão sendo tomadas para melhorar a estrutura do município, sendo duas delas o Parque Linear (Projeto ORLA) e a priorização da implantação do tratamento de coleta e rede de esgotos em todo o município. Acredita-se que, com estas ações, o município inicie uma nova fase de de- 
senvolvimento, valorizando o que tem de melhor, e, contribuindo uma gestão turística sustentável.

Considera-se neste sentido, que novos estudos devam ser desenvolvidos para identificar a percepção destes mesmos agentes após a intervenção do setor público e empresários com as ações projetadas e planejadas para os próximos anos, especialmente quanto à implantação do Projeto ORLA, que apresenta condições de maximizar a qualidade do turismo de Itapema e Meia Praia e focar esforços na gestão da sustentabilidade ambiental.

\section{Referências bibliográficas}

ALEXANDRE, L.M.M. Política de turismo e desenvolvimento local: binômio necessário. In: BEZERRA, D.M.F. (Org.). Planejamento e gestão em turismo. São Paulo: Rocca, 2003.

ANJOS, F.A. dos. Processo de planejamento e gestão de territórios turísticos. Tese (Doutorado em Engenharia de Produção). Universidade Federal de Santa Catarina, 2004.

ANJOS, F.A. dos; ANJOS, S.J.G. dos; RADOS, G.J.V. Planejamento e gestão sustentável do turismo: contexto social, métodos e enfoques. In: PHILIPPI-Jr.; A. (Coord.). Gestão ambiental e sustentabilidade no turismo. São Paulo: Manole, 2010. cap. 8, pp. 128-150. (Coleção Ambiental).

ASSOCIAÇÃO BRASILEIRA DE NORMAS TÉCNICAS. Instituto de Hospitalidade. Norma nacional - NIH-54. Meios de hospedagem: requisitos para a sustentabilidade. Salvador: Instituto de Hospitalidade, 2004.

BACKER, P. de. Gestão ambiental: a administração verde. Rio de Janeiro: Qualitymark, 1995.

BRASIL perde posições em ranking mundial do turismo. Jornal O Estado de São Paulo. Disponível em: <http://www.estadao.com.br/noticias/nacional,brasil-perdeposicoes-em-ranking-mundial-do-turismo,688917,0.htm>. Acesso em: 15 jan. 2012.

BRASIL. Resolução CONAMA n ${ }^{\circ}$ 237, de 19 de dezembro de 1997. Dispõe sobre os procedimentos e critérios para o licenciamento ambiental, e dá outras providências. Lex: Disponível em: <http://www.mma.gov.br/port/conama/res/res97/res23797.htm>. Acesso em: 11 maio 2006.

BUTLER, R. W. The concept of a tourist area life cicle of evolution implications for management of resources. Canadian Geographer, v. 24, n.4, p.p5-12, 1980.

CALLENBACH, E.; CAPRA, F..GOLDMAN, L.; LUTZ, R.; MARBURG, S. Gerenciamento Ecológico - (Eco - Management) - Guia do Instituto Elmwood de Auditoria Ecológica e Negócios Sustentáveis. São Paulo: Cultrix, 1993. 
CHOI, HwanSuk Chris; SIRAKAYA, Ercan. Sustainability indicators for managing community tourism. Tourism Management, New York, 2006, pp.1274-1289.

COOPER, C.; HALL, C. M.; TRIGO, L. G. G..Turismo contemporâneo. Rio de Janeiro: Elsevier, 2011. (Coleção Eduardo Sanovicz de Turismo).

DIAS, Reinaldo. Turismo sustentável e meio ambiente. São Paulo: Atlas, 2003.

DÍAZ, M.R.; RODRíGUEZ, T.F.E. A Model of Strategic Evaluation of a Tourism Destination Based on Internal and Relational Capabilities. Journal of Travel Research, USA, may, 2008, pp. 368-380.

FARIAS, V.F. Itapema: natureza, história, cultura. Itapema: Ed. do autor. 1999.

GARTNER, W. C. Image. In: JAFARI, J. Encyclopedia of tourism. London: Routledge, 2000, pp. 295-296.

GONÇALVES, L. C. Gestão ambiental em meios de hospedagem. São Paulo: Aleph, 2004.

INSTITUTO BRASILEIRO DE GEOGRAFIA E ESTATÍSTICA (IBGE). Recuperação Automática-SIDRA e VII Recenseamento Geral do Brasil. Disponível em: <http:// www.ibge.gov.br>. Acesso em: 14 jan. 2012.

JUNQUEIRA, Luiz Daniel Muniz. Lago Paranoá de Brasília - DF: análise dos usos e ocupações do espaço da orla para o lazer. Dissertação (Mestrado em Turismo e Hotelaria) - Universidade do Vale do Itajaí, Balneário Camboriú, 2006. 285 f.

KANNI, F. Sustentabilidade e responsabilidade sócio-ambiental nas empresas turísticas: a certificação ambiental no segmento de hospedagem. In: RUSCHMANN, D. van de M.; SOLHA, K. Turismo: uma visão empresarial. São Paulo: Manole, 2004, cap. 9 , pp. 91-113.

HALL, C. M. Planejamento turístico: política, processos e relacionamentos. São Paulo: Contexto, 2001.

HUGHES, J. A filosofia da pesquisa social. Rio de Janeiro: Zahar Editores, 1980, pp. 70-124.

LEFÈVRE, F.; LEVÈVRE, A.M.C. O Discurso do sujeito coletivo: um novo enfoque em pesquisa qualitativa (desdobramentos). Caxias do Sul, RS: EDUCS, 2003.

LERÍPIO, A.A.; CAMPOS, L.M.S. Auditoria ambiental: uma ferramenta de gestão. São Paulo: Atlas, 2009.

LERIPIO, A. A. Gerenciamento de resíduos. Disponível em: <http://www.eps.ufsc.br/ ugga/Coferecidos.html>. Acesso em: 12 dez. 2004.

MINISTÉRIO DO MEIO AMBIENTE; MINISTÉRIO DO PLANEJAMENTO, ORÇAMENTO E GESTÃO. Projeto ORLA: manual de gestão. Brasília, DF: MMA, 2006. 
MINISTÉRIO DO TURISMO. Programa de regionalização do turismo. Disponível em: $<$ http://turismo.org.br>. Acesso em: 23 mar. 2007.

MINAYO, M.C.S. (Org.). Pesquisa social: teoria, método e criatividade. 12. ed. Petrópolis, Rio de Janeiro: Vozes, 1999.

MOLINA, S. Planejamento integral do turismo. Bauru: Edusc, 2001.

OLIVEIRA, R.A. Desenvolvimento turístico e transformações sócio-espaciais no município de Itapema-SC. 2002. Dissertação (Mestrado em Turismo e Hotelaria) - Universidade do Vale do Itajaí, Itajaí, 2002.

ORGANIZAÇÃO DAS NAÇÕES UNIDAS (ONU). Green economy in the context of sustainable development and poverty eradication. United Nations Conference on Sustainable Development. Isponível em <http://www.uncsd2012.org/rio20/index.php? menu=62>. Acesso em 10 jan. 2012.

ORGANIZAÇÃO MUNDIAL DO TURISMO. Desenvolvimento de turismo sustentável: manual para organizadores locais. Madrid: Organización Mundial del Turismo, 1994.

OYOLA, M.L.; BLANCASA, F.J.; GONZÁLEZ, M.; CABALLERO, R. Sustainable tourism indicators as planning tools in cultural destinations. Ecological Indicators. Elsevier, 2012, pp. 659-675.

PREFEITURA MUNICIPAL DE ITAPEMA. Disponível em: <http:// www.itapema.sc.gov.br>. Acesso em: 25 abr. 2007.

PREFEITURA MUNICIPAL DE ITAPEMA. Disponível em: <http:// www.itapema.sc.gov.br>. Acesso em: 12 jan. 2012.

RUSCHMANN, D.van de M. Turismo e planejamento sustentável: a proteção do meio ambiente. 6. ed. Campinas: Papirus, 2001. (Coleção Turismo).

SANTA CATARINA TURISMO (SANTUR). Costa Verde e Mar - Itapema. Disponível em: <http://www.santur.sc.gov.br/destinos/costa-verde-e-mar/1030-itapema.html> Acesso em: 10 maio 2009.

SANTOS, N. Gestão estratégica do conhecimento. Apostila publicada do Programa de Pós-Graduação em Engenharia e Gestão do Conhecimento, Universidade Federal de Santa Catarina (UFSC): Florianópolis, 2005.

SANTOS, C.A.J.; CAMPOS, A.C. Estratégias para o desenvolvimento sustentável do turismo. In: CORIOLANO, L. (Org.). Turismo comunitário e responsabilidade socioambiental. Fortaleza: EDUECE, 2003, pp. 161-172.

SCHRAMM,W. Notes on case studies of instructional media projects. Workingpaper,the Academy for Educational Development,Washington, DC., 1971.

SACHS, I. Estratégias de transição para o século XXI. São Paulo: Nobel,1997. 
SACHS, I. Desenvolvimento: includente, sustentável, sustentado. Rio de Janeiro: Garamond, 2008.

SECRETARIA DE ESTADO DO PLANEJAMENTO DE SANTA CATARINA. Dados estatísticos municipais. Disponível em: <http://www.spg.sc.gov.br/dados munic.php > Acesso em: jun. 2007.

SILVA, M.E.M. da. O sistema turístico de Meia Praia - ItapeLma e suas implicações no meio ambiente, sob a perspectiva da sustentabilidade. Monografia. $216 \mathrm{f}$. (Especialização em Gestão Ambiental). Universidade do Vale do Itajaí, Itajaí, 2007.

WORLD TOURISM ORGANIZATION (WTC). Indicators of Sustainable Development for Tourism Destinations. A Guidebook. Madrid: World Tourism Organization, 2004.

\section{Agradecimentos}

O presente trabalho é resultado de monografia do Curso de Pós-Graduação em Gestão Ambiental, concluída em 2007 pela Universidade do Vale do Itajaí. Inúmeros dados da pesquisa foram alcançados com apoio da Prefeitura Municipal de Itapema, ao qual prestamos nossos agradecimentos.

Maria Emília Martins da Silva: Instituto Federal de Educação, Ciência e Tecnologia Catarinense, Sombrio, SC, Brasil.

Email: mariaemilia.martins@ibest.com.br

Link para o currículo Lattes: http://lattes.cnpq.br/6360749673483284

Francisco Antônio dos Anjos: Universidade do Vale do Itajaí, Balneário Camboriú, SC, Brasil.

Email: fsanjos@terra.com.br

Link para o currículo Lattes: http://lattes.cnpq.br/5675009830173154

Data de submissão: 19 de fevereiro de 2012

Data de recebimento de correções: 02 de maio de 2012

Data do aceite: 02 de maio de 2012

Avaliado anonimamente 